\title{
Pemodelan Bayesian Network untuk Prediksi Penyakit Saluran Pernapasan
}

\author{
Novi Indah Pradasari ${ }^{1}$; Rizqia Lestika Atimi ${ }^{2}$ \\ ${ }^{1,2}$ Politeknik Negeri Ketapang \\ ${ }^{1}$ noviindah.ti@gmail.com
}

\begin{abstract}
This Bayesian network model was developed by analyzing the correlation between the cause of disease symptom variables and disease variables. The Bayesian network is a method that can depict causality between variables in a system. In this research, the Bayesian network was developed with a scoring based method and it was implemented using a hill-climbing algorithm with scoring BIC score function approach. There were 18 variables and 31 arcs representing the interconnection between symptom variable and respiratory tract disease. In the testing phase, the inference process using approximate inference was carried out and the accuracy was nearly $100 \%$ for all testing scenarios. The application of this method could result in a representative Bayesian network. Its resulted structure was affected so much by data condition, thus data cleaning was important to do before training and testing phase.
\end{abstract}

Keywords: Approximate inference, Bayesian Network, BIC score, hill-climbing, scoring based

\begin{abstract}
ABSTRAK
Model Bayesian Network ini dikembangkan dengan menganalisis korelasi antara penyebab variabel gejala penyakit dan variabel penyakit. Bayesian network adalah metode yang dapat menggambarkan hubungan sebab akibat antar variabel dalam suatu sistem. Dalam penelitian ini, Bayesian Network dikembangkan dengan metode scoring based dan diimplementasikan menggunakan algoritma hill climbing dengan pendekatan BIC Score. Ada 18 variabel dan 31 arc yang mewakili interkoneksi antara variabel gejala dan penyakit saluran pernapasan. Dalam fase pengujian, proses inferensi menggunakan approximate inference dilakukan dan akurasi hampir 100\% untuk semua skenario pengujian. Pengaplikasian metode ini dapat menghasilkan bayesian network yang representatif. Struktur yang dihasilkan sangat dipengaruhi oleh kondisi data, oleh karena itu pembersihan data penting dilakukan sebelum tahap pelatihan dan pengujian.
\end{abstract}

Kata kunci: Approximate inference, Bayesian Network, BIC score, hill-climbing, scoring based 


\section{PENDAHULUAN}

Penyakit saluran pernapasan adalah penyakit yang terjadi akibat adanya gangguan pada organ pernapasan yang menyebabkan kerja dari organ saluran pernapasan tersebut menjadi tidak normal (Asih 2002). Menurut catatan WHO tahun 2012 ratusan juta orang di seluruh dunia menderita penyakit pernapasan kronis, sebanyak 235 juta orang menderita asma, 64 juta orang memiliki Penyakit Paru Obstruktif Kronik (PPOK), sementara jutaan lainnya menderita penyakit pernapasan kronis namun tidak terdiagnosis. Penyakit saluran pernapasan adalah penyakit yang secara diamdiam dapat membunuh, namun kasus ini sering diabaikan. [1]

Untuk mendiagnosis penyakit saluran pernapasan, dokter membutuhkan hipotesis untuk menentukan jenis penyakit saluran pernapasan, sehingga pasien dapat ditangani dengan cepat. Untuk mengetahui seseorang itu terkena penyakit saluran pernapasan atau tidak, perlu dilakukan pemeriksaan oleh dokter, namun pada kenyataannya seorang dokter memiliki keterbatasan daya ingat dikarenakan faktor umur/usia, sehingga seorang dokter bisa saja melakukan kesalahan yang mungkin salah satunya kesalahan pada hasil diagnosis yang berlanjut pada kesalahan solusi yang diambil. Selain biaya pemeriksaan yang relatif mahal, seorang dokter juga memiliki jam praktek yang terbatas sehingga masyarakat tidak setiap waktu dapat terlayani.

Alternatif dari pemecahan masalah ini adalah dengan membangun sebuah model untuk mendiagnosis penyakit saluran pernapasan. Dengan model yang dibuat ini, masalah mengenai keterbatasan jam kerja dari dokter dalam memberikan diagnosis awal terhadap pasien penyakit saluran pernapasan dapat diatasi, selain itu pengetahuan dan pengalaman dari dokter dapat dipelihara agar dapat memberikan hasil diagnosis penyakit secara tepat dan efektif.

Menurut Fishman et al. (2008) terdapat beberapa jenis penyakit saluran pernapasan. Penelitian yang dilakukan ini difokuskan untuk enam jenis penyakit saluran pernapasan, yaitu: Asma, Infeksi Saluran Pernapasan Akut (ISPA), Pneumonia, Bronkhitis, Sinusitis, dan Tuberkulosis. Adapun dari enam jenis penyakit saluran pernapasan ini memiliki 12 gejala yang merupakan gejala awal dari timbulnya penyakit-penyakit pernapasan. Gejala-gejala tersebut antara lain: sesak napas, batuk, nyeri dada, demam, lelah, mual dan muntah, menggigil, hidung tersumbat, sakit kepala, berat badan turun, berkeringat dingin, serta kekakuan sendi [2]. Gejala-gejala dan jenis penyakit ini akan menjadi variabel dalam melakukan diagnosis penyakit saluran pernapasan.

Penelitian ini bertujuan untuk membangun model yang merepresentasikan hubungan antar variabel gejala dan penyakit menggunakan Bayesian Network, serta menggunakan model yang dihasilkan untuk mendiagnosis penyakit saluran pernapasan. dalam hal ini Bayesian Network dapat digunakan untuk menghitung probabilitas dari kehadiran berbagai gejala penyakit dengan memperhatikan gejala-gejala yang dialami. Bayesian Network terdiri dari 2 bagian utama, yaitu membangun struktur DAG (directed acylic graph) dan menghitung CPT (Conditioal probability table). [3][4]

Saat ini telah dikembangkan metode learning yang memungkinkan untuk membangun struktur Bayesian Network secara langsung dari basis data. Metode-metode tersebut antara lain metode search and scoring (scored based) dan dependency analysis (constraint based). Pada metode search and scoring dilakukan pencarian untuk mendapatkan struktur yang cocok dengan data, dimana proses konstruksi dilakukan secara iteratif, dimulai dari sebuah graf tanpa edge kemudian menggunakan metode pencarian untuk menambahkan sebuah edge pada graf dan berhenti ketika tidak ada struktur baru yang lebih baik dari pada struktur sebelumnya, sedangkan pada metode depedency analysis, Bayesian Network dipandang sebagai sebuah struktur yang merepresentasikan sekumpulan kebebasan kondisional di antara variabel .[3][4] 
Pada penerapannya sendiri, Bayesian Network telah banyak diterapkan dalam bidang kesehatan, khususnya untuk mendiagnosis berbagai jenis penyakit. Penelitian sebelumnya dilakukan oleh Daniel-Ioan et al. (2009) yang mana pada penelitian ini Bayesian Network digunakan untuk membuat suatu keputusan medis pada diagnosis penyakit kejiwaan. Pada pembangunan model ini Bayesian Network digunakan untuk melihat hubungan antar faktor-faktor dengan hasil diagnosis. Kemudian penelitian yang dilakukan oleh M.Berkan Sesen et al (2013), dengan menggunakan model Bayesian Network untuk mendiagnosis penyakit kanker paru-paru dengan menggunakan data dari LUCADA dimana dari data tersebut dilakukan diagnosis untuk kemudian diberikan pengobatan sesuai dengan stadium yang diderita oleh pasien berdasarkan hasil diagnosisnya, selanjutnya akan mendiagnosis kelangsungan hidup pasien tersebut dalam jangka waktu 1 tahun. Selanjutnya penelitian dilakukan oleh Seixas et al. (2014) yang mana Bayesian Network digunakan untuk mendukung diagnosis untuk diagnosis penyakit Dementia, Alzaimer Disease ( $A D$ ) dan Mild Cognitive Impairment (MCI) yaitu penyakit yang terjadi karena fenomena penuaan. Atribut dataset terdiri dari faktor predisposal, hasil tes neuropsikologi pasien data demografis, gejala dan ciri-ciri dari masing-masing penyakit.[5][6]

Berdasarkan penelitian sebelumnya Bayesian Network menghasilkan akurasi yang baik untuk diagnosis penyakit, sehingga pada penelitian ini Bayesian Network digunakan untuk mendiagnosis penyakit saluran pernapasan. Penelitian yang akan dilakukan ini meliputi pembangunan struktur Bayesian Network, menentukan parameter masing-masing gejala dan penyakit, dan Inferensi probabilistik.

\section{METODE/PERANCANGAN PENELITIAN}

Tahapan Penelitian

Metode penelitian yang dilakukan dalam membangun model Bayesian Network untuk mendiagnosis penyakit saluran pernapasan ini terdiri atas beberapa tahap, yaitu (1) Identifikasi permasalahan, (2) pengumpulan data, dan (3) Penerapan metode Bayesian Network. Diagram alir dari penelitian ini dapat dilihat pada Gambar 1 .

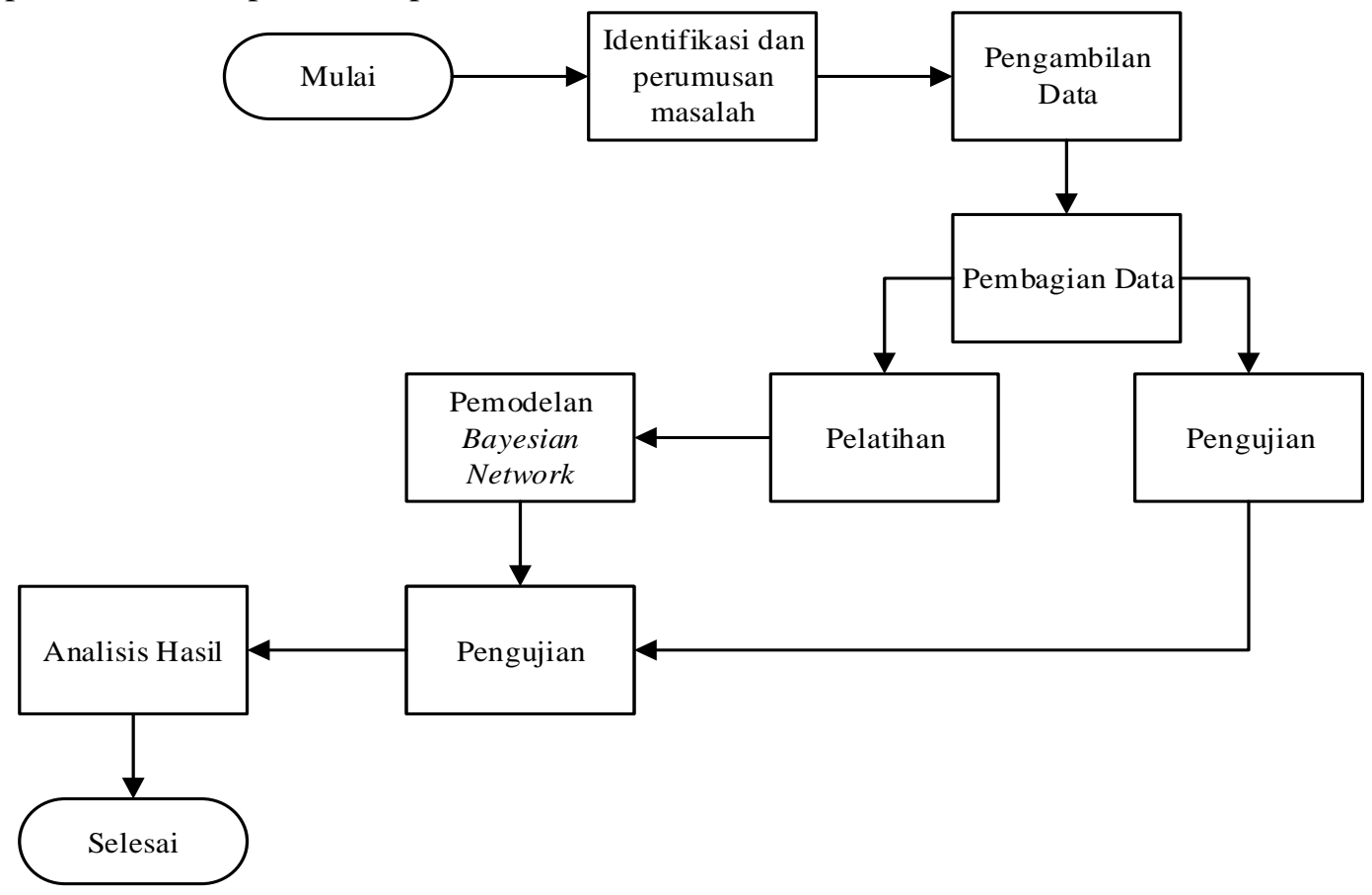

Gambar 1. Flowchart Penelitian 


\section{Pengumpulan Data}

Data yang digunakan pada penelitian ini adalah data rekam medik RSUD Agoes Djam. Data yang diambil adalah data rekam medik untuk penyakit saluran pernapasan. Data yang terkumpul sebanyak 120 buah data untuk enam jenis penyakit saluran pernapasan, antara lain: Asma, ISPA, Pneumonia, Bronkhitis, Sinusitis dan Tuberkulosis. Masing-masing penyakit memiliki 20 data rekam medik.

Data rekam medik yang didapat kemudian digunakan sebagai data pelatihan dan pengujian dalam pemodelan Bayesian Network. Data rekam medik yang digunakan ini berupa gejala-gejala serta jenis dari penyakit saluran pernapasan, yang akan digunakan untuk mendiagnosis enam jenis penyakit saluran pernapasan. Data tersebut dibagi $60 \%$ untuk pelatihan, dan $40 \%$ untuk pengujian.

\section{Penerapan Metode Bayesian Network}

Dalam penelitian ini digunakan 18 buah variabel gejala dan penyakit. Untuk memodelkan keterhubungan antara 18 variabel ini, dibangun sebuah model struktur Bayesian Network dari data dengan menggunakan software Rstudio Version 0.98.1014. Model yang dihasilkan akan digunakan untuk mendiagnosis penyakit saluran pernapasan.

Secara umum alur kerja dari model yang akan dibagun ini terdiri dari 6 tahapan seperti pada Gambar 2, yaitu praproses data, membangun struktur Bayesian Network, visualisasi struktur Bayesian Network, menghitung parameter leraning dari struktur Bayesian Network, dan inferensi, yaitu pengambilan keputusan.

- Praproses data, dimana data merupakan hal yang sangat penting sebelum melakukan penelitian. Akurasi data maupun kebenaran data itu sangat penting dalam penelitian, karena data yang tidak berkualitas maka akan menghasilkan keluaran yang tidak berkualitas juga, sehingga pengambilan data harus sesuai dengan data sebenarnya. Maka dari itu pada penelitian ini perlu adanya data cleaning, adapun tugas dari data cleaning pada penelitian ini adalah untuk memperbaiki ketidakkonsistenan data yang diperoleh.

- Struktur Bayesian Network dapat digambarkan berdasarkan data gejala dan data penyakit yang diperoleh dari proses studi literatur dan dari data yang diperoleh, pada penelitian ini menggunakan pendekatan metode scoring based, yaitu suatu metode pencarian untuk membangun model dan mengevaluasi model tersebut berdasarkan nilai skor. Pada penelitian ini, proses penghitungan skor akan berlanjut dan berhenti jika suatu nilai model tidak mempunyai perbedaan yang lebih signifikan yang dibandingkan model yang sebelumnya. Metode scoring based ini dapat diselesaikan dengan beberapa algoritme, salah satunya yang digunakan pada penelitian ini adalah algoritme HC (Hill climbing). Dimana Hill climbing merupakan suatu metode pencarian heuristik yang bekerja secara greedy. Pada penelitian ini, algoritme Hill climbing memberikan skor/nilai terhadap masing-masing parameter untuk menentukan tingkat keterhubungan dari masing-masing parameter dengan menggunakan fungsi scoring BIC score.

- Setelah didapat skor untuk masing-masing node yang saling terhubung, selanjutnya node tersebut divisualisasikan dalam bentuk directed acylic graph (DAG).

- Selanjutnya, setelah struktur Bayesian Network untuk penyakit saluran pernapasan terbentuk, dilakukan penghitungan parameter untuk mendapatkan nilai conditional Probability table (CPT), yaitu nilai yang merepresentasikan nilai probabilitas dari suatu kejadian, setelah kejadian sebelumnya sudah terjadi, pada perhitungan nilai parameter learning menggunakan Bayesian Estimation. 
- Sedangkan tahap terakhir adalah inferensi, yaitu pada penelitian ini untuk pengujian, untuk melihat seberapa akurat model yang dibangun tersebut dalam mendiagnosis penyakit saluran pernapasan. Tahap inferensi dilakukan dengan pendekatan Approximate Inference.

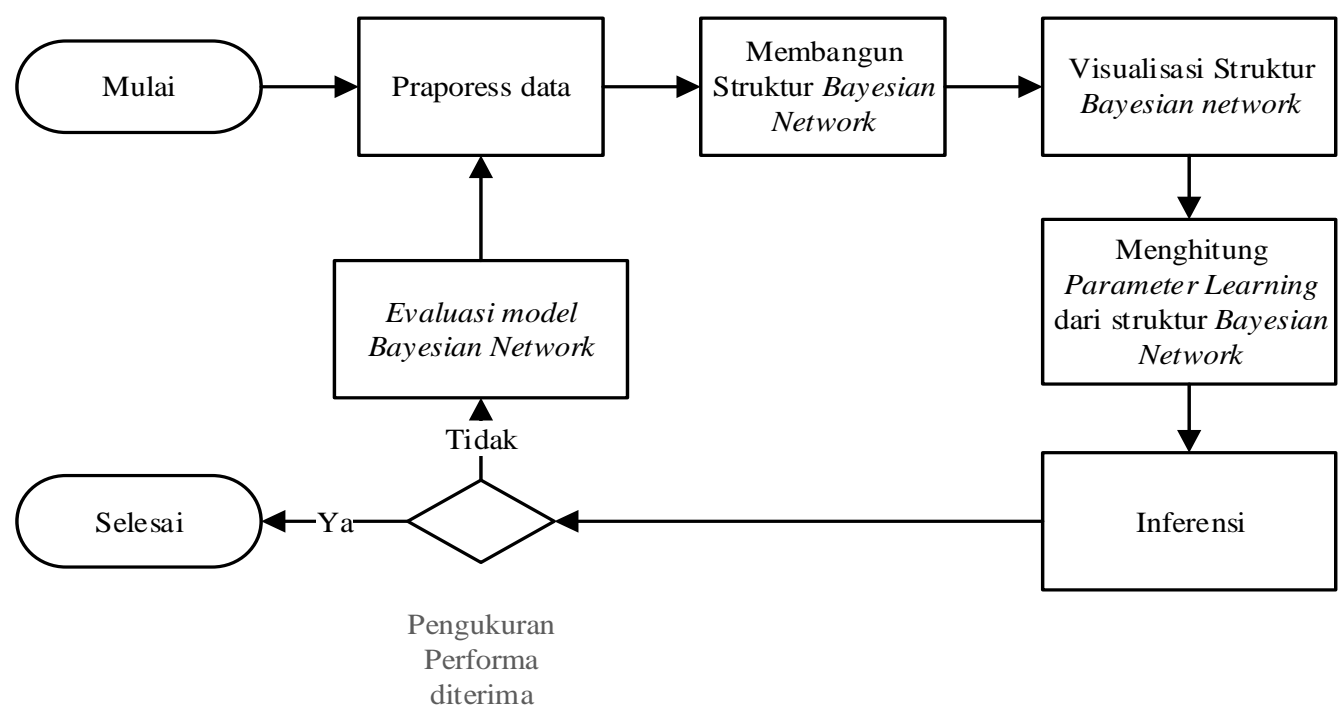

Gambar 2. Penerapan metode Bayesian Network

\section{HASIL DAN PEMBAHASAN}

\section{Hasil Penelitian}

Dalam penelitian ini, terdapat enam jenis penyakit saluran pernapasan dengan 12 gejala yang menyertainya, oleh sebab itu pada pembangunan model ini menggunakan metode Bayesian Network dikarenakan metode ini dapat merepresentasikan hubungan sebab akibat antara penyakit dan gejalanya, serta dapat menghitung probabilitas gejala dari suatu penyakit, sehingga mempermudah pengguna dalam menentukan jenis penyakit saluran pernapasan yang diderita. Pada Bayesian Network semua parameter adalah variabel sehingga setiap parameter memiliki nilai sebaran distribusi.

Data rekam medik yang digunakan pada penelitian ini diambil dari data medical record RSUD Agoes Djam Ketapang selama 4 Tahun (dari 2015-2018). Data yang digunakan sebanyak 120 data. Data yang diperoleh tersebut berupa informasi mengenai gejala yang diderita oleh pasien penyakit saluran pernapasan, sehingga ini mendukung untuk diterapkan dengan metode Bayesian Network.

Terdapat beberapa langkah dalam menerapkan metode Bayesian Network, berikut langkahlangkah dan penjelasan dari metode yang dilakukan:

1. Membangun struktur Bayesian Network untuk diagnosis penyakit saluran pernapasan. Penelitian diawali dengan merumuskan masalah yang akan diteliti dalam penelitian. Pada penelitian ini model Bayesian Network dibangun dengan perangkat lunak Rstudio Version 0.99.903. Struktur ini dibentuk dengan menggunakan metode Hill-Climbing yang merupakan metode populer untuk pembentukan Bayesian Network dari data. Dengan menggunakan skor BIC untuk mendapatkan struktur Bayesian Network berkualitas tinggi dengan waktu yang wajar. Berikut adalah instruksi yang digunakan untuk pembentukan structure learning pada pembentuk stuktur Bayesian Network.

$>$ library(bnlearn)

$>$ network=hc(data, score="BIC", max.iter=1000) 
Iterasi pada algoritme Scoring based mengasumsikan bahwa node tersebut dalam keadaan terurut dan dimulai dari struktur yang tidak mempunyai jaringan, dan proses pembentukan jaringan akan berhenti jika telah memenuhi jumlah iterai. Dalam urutan tersebut ada aturan bahwa node pada urutan awal tidak mungkin menjadi child bagi node urutan berikutnya. Pembentukan model struktur Bayesian Network menggunakan algoritme Scoring based dengan bantuan perangkat lunak Rstudio Version 0.99.903. Hasil keluarannya dapat dilihat pada Gambar 3.

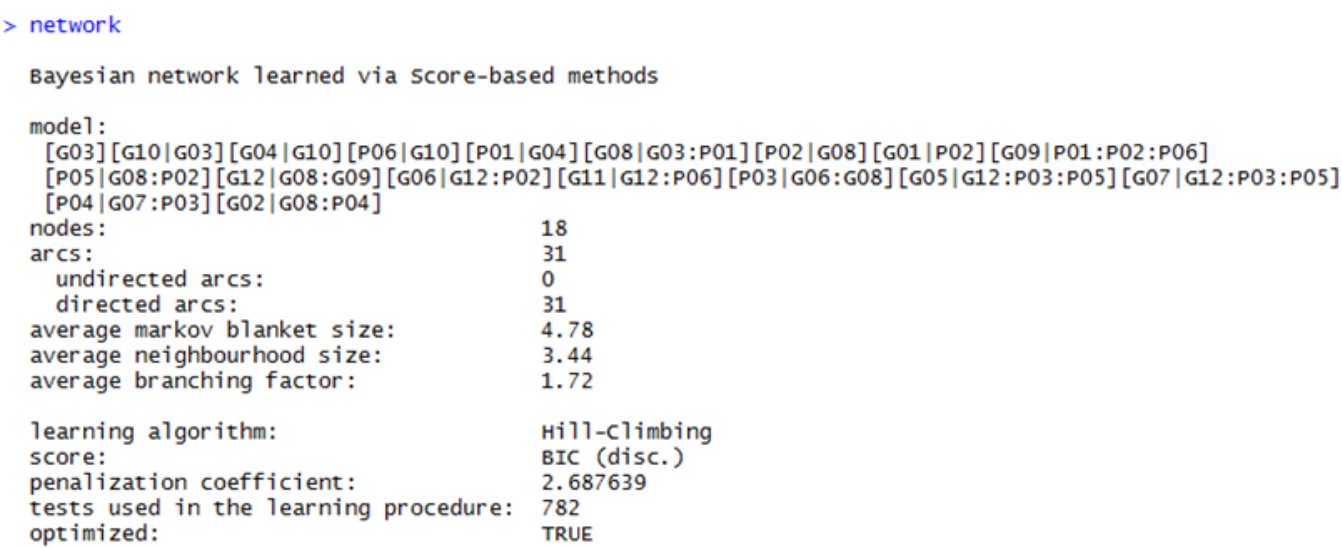

Gambar 3. Hasil Konstruksi Bayesian Network dengan Score Based

2. Visualisasi Struktur Bayesian Network

Dari hasil tersebut, dapat dilihat bahwa dengan menggunakan algoritme scoring based dengan penerapan Hill climbing dan pendekatan dengan BIC(Bayesian Information Criterion) score, didapat 31 arcs yang terbentuk dari 18 buah variabel, sehingga struktur Bayesian Network yang didapat seperti pada Gambar 4.

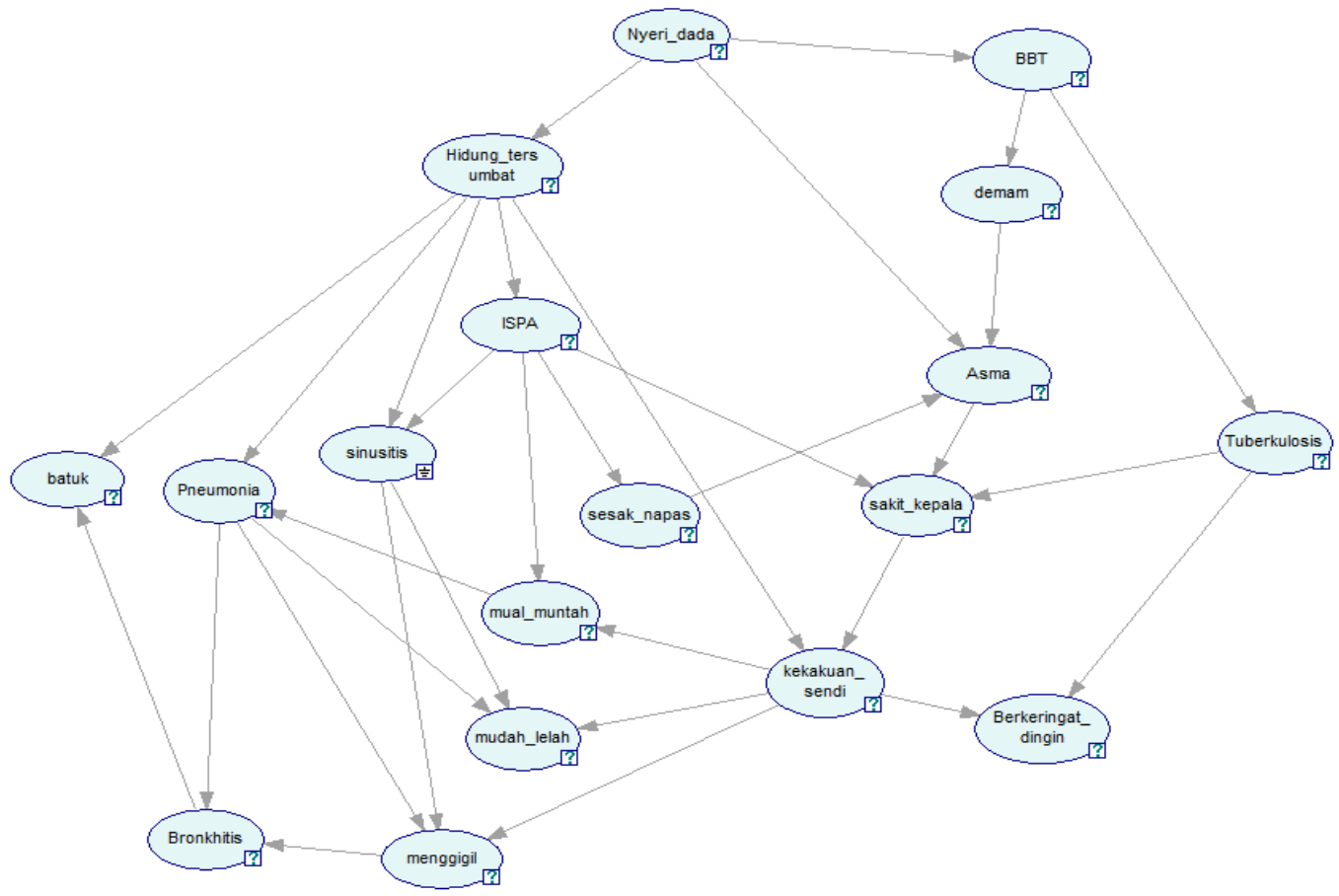

Gambar 4. Struktur Bayesian Network 


\section{3. $\quad$ Menghitung Parameter Learning}

Dari struktur pada Gambar 4 dapat diketahui adanya keterkaitan antar variabel data untuk diagnosis penyakit saluran pernapasan. Selanjutnya setelah struktur Bayesian Network terbentuk, dilakukan pengitungan setiap node untuk menghasilkan nilai masing-masing parameter yang menunjukkan besar nilai probabilitas dari masing-masing variabel. Pada perhitungan parameter learning ini sendiri menggunakan Bayesian Estimation, yaitu perhitungan dilakukan dengan menggunakan data untuk mendapatkan nilai CPT (Conditional Probability Table).

Sebagai contoh, berdasarkan struktur pada Gambar 4, dapat diidentifikasi keterkaitan antara variabel mudah_lelah yang menunjukkan adanya keterkaitan dengan Pneumonia, Sinusitis dan Kekakuan sendi. Tabel 1 menunjukkan parameter untuk variabel mudah_lelah.

Tabel 1. Parameter variabel mudah_lelah

\begin{tabular}{c|c|c|c|c|c|c|c|c}
\hline P03 & \multicolumn{3}{|c|}{ Pneumonia } & \multicolumn{4}{c}{ Tidak } \\
\hline P05 & \multicolumn{2}{|c|}{ Sinusitis } & \multicolumn{2}{c|}{ Tidak } & \multicolumn{2}{c}{ Sinusitis } & \multicolumn{2}{c}{ tidak } \\
G12 & Kaku_sendi & Tidak & Kaku_sendi & tidak & Kaku_sendi & tidak & Kaku_sendi & tidak \\
\hline Mudah_lelah & 0.50 & 0.50 & 0.016 & 0.50 & 0.77 & 0.028 & 0.66 & 0.64 \\
Tidak & 0.50 & 0.50 & 0.98 & 0.50 & 0.22 & 0.971 & 0.33 & 0.35 \\
\hline
\end{tabular}

Selanjutnya, berdasarkan struktur Bayesian Network pada Gambar 4 juga dapat diidentifikasi keterkaitan variabel penyakit Pneumonia dengan variabel hidung_tersumbat, dan variabel mual_dan_muntah. Parameter variabel dari penyakit Pneumonia dapat dilihat pada Tabel 2.

Tabel 2. Parameter variabel Pneumonia

\begin{tabular}{c|c|c|c|c|c|c|c|c}
\hline G08 & \multicolumn{4}{|c|}{ Hidung_tersumbat } & \multicolumn{4}{c}{ Tidak } \\
G06 & Mual & Mual_dan_muntah & Muntah & Tidak & Mual & Mual_dan_muntah & muntah & tidak \\
\hline Pneumonia & 0.50 & 0.016 & 0.50 & 0.014 & 0.14 & 0.98 & 0.075 & 0.006 \\
Tidak & 0.50 & 0.98 & 0.50 & 0.98 & 0.85 & 0.016 & 0.924 & 0.993 \\
\hline
\end{tabular}

\section{Pengujian dan Pembahasan}

Pada tahap pengujian, dilakukan dengan menggunakan Approximate Inference, dimana hasil yang didapat dengan menggunakan approximate inference mendekati peluang sebenarnya. Pada penelitian ini, Approximate Inference digunakan untuk mengevaluasi hasil yang diperoleh pada structure learning dan parameter learning.

Data yang digunakan sebagai data uji adalah data yang diambil dari rekam medik rumah sakit yang tidak digunakan sebagai dataset dalam proses konstruksi Bayesian Network. Hasil diagnosis yang dihasilkan akan dibandingkan dengan hasil rekam medik yang diperoleh. Agar pengujian optimal, maka data pengujian diambil secara acak dari dataset. Pengujian dilakukan untuk mengetahui seberapa besar keakuratan sistem. Pengujian sistem dilakukan untuk 36 data sebagai sample dengan pembagian 6 data untuk masing-masing penyakit.

Pada penelitian ini, pengujian dilakukan dengan cara menghitung probabilitas gejala-gejala terhadap semua jenis penyakit saluran pernapasan, yang kemudian hasilnya akan dibandingkan dengan diagnosa sebenarnya pada data uji. Apabila hasil menunjukkan nilai probabilitas tinggi pada pengujian penyakit tersebut, maka diagnosa dikatakan benar, namun apabila hasil pengujian menunjukkan nilai probabilitas yang dihasilkan rendah pada penyakit yang sedang 
diujikan jika dibandingkan dengan penyakit lainnya, maka diagnosa dikatakan tidak tepat. Berikut adalah hasil pengujian dari model yang dibuat:

1. Pengujian Penyakit Asma dengan menggunakan sample data secara acak, didapat hasil seperti pada Gambar 5:

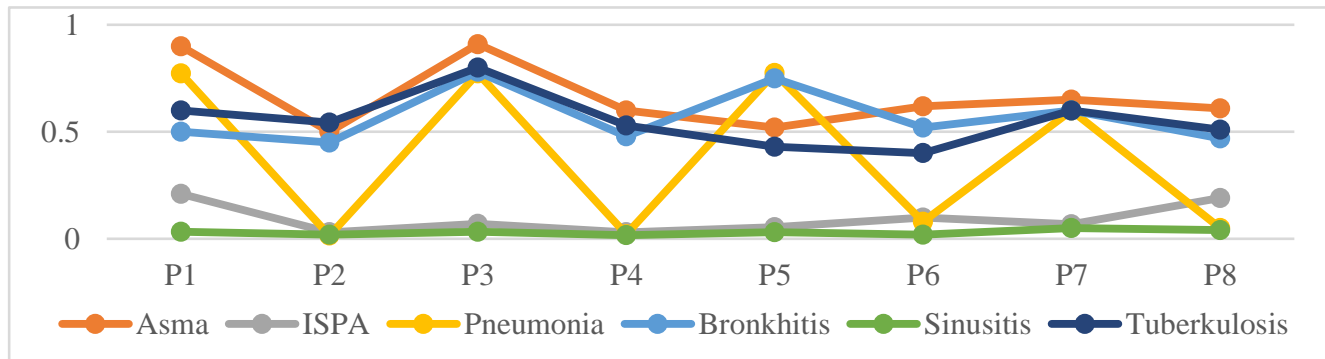

Gambar 5. Hasil Pengujian penyakit Asma

Dari Gambar 5 dengan P1 sebagai pengujian pertama sampai dengan P8 pengujian delapan, dapat dilihat bahwa probabilitas tertinggi ada pada penyakit Asma, namun pada pengujian ke 2 dan ke 5, penyakit dengan probabilitas tertinggi ada pada penyakit tuberkulosis. Setelah dilakukan analisis dengan data, hal ini disebebakan karena gejala untuk penyakit asma dan tuberkulosis memiliki kesamaan, yaitu gejala penyakit asma mendekati gejala untuk penyakit tuberkulosis, sehingga probabilitas untuk penyakit Asma mendekati probabilitas untuk penyakit Tuberkulosis.

2. Pengujian Penyakit ISPA dengan menggunakan sample data secara acak dari data, didapat hasil seperti pada Gambar 6 :

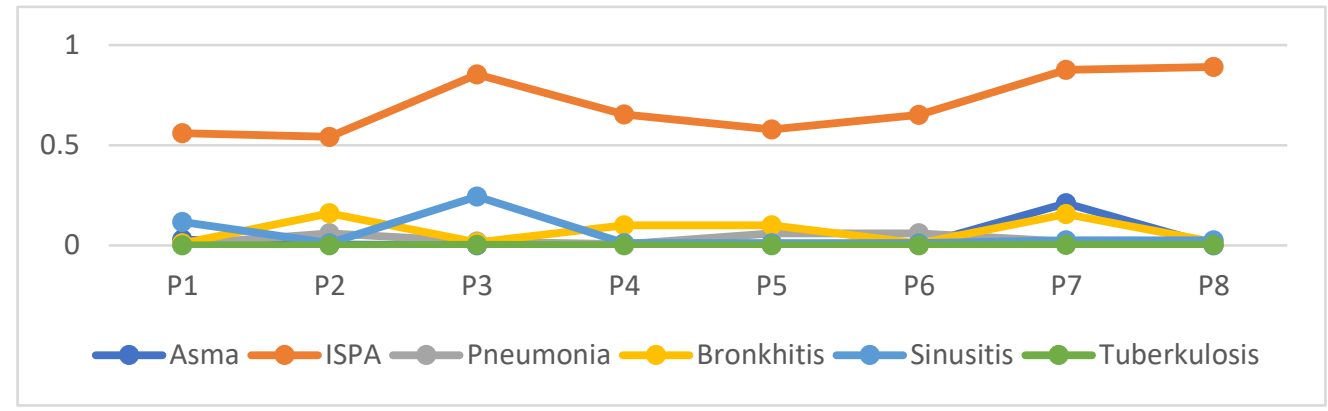

Gambar 6. Hasil Pengujian penyakit ISPA

Dari Gambar dapat dilihat bahwa hasil pengujian menunjukkan bahwa pada pengujian 1 sampai pengujian 8 mendapatkan nilai probabilitas tertinggi untuk diagnosis penyakit ISPA. Pada Gambar 6 juga dapat dilihat hasil untuk penyakit Asma, ISPA, Pneumonia, Bronkhitis dan Sinusitis, memiliki nilai probabilitas yang rendah dapat dilihat pada grafik yang dihasilkan sangat signifikan. Hal ini disebabkan karena pada penyakit ISPA memiliki gejala yang berbeda diantara penyakit lainnya. 
3. Pengujian Penyakit Pneumonia dengan menggunakan sample data secara acak, didapat hasil seperti pada Gambar 7:

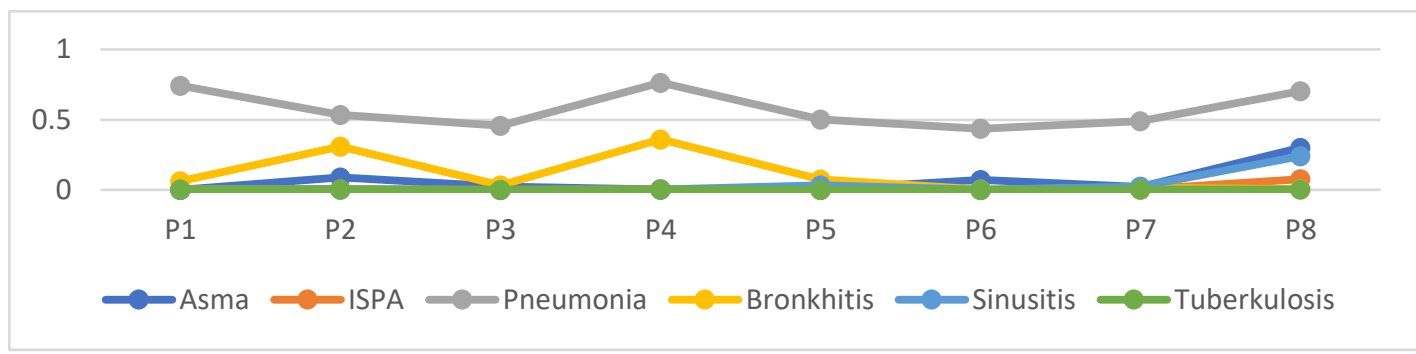

Gambar 7. Hasil Pengujian penyakit Pneumonia

Dari Gambar dapat dilihat bahwa hasil pengujian menunjukkan bahwa pada pengujian 1 sampai pengujian 8 mendapatkan nilai probabilitas tertinggi untuk diagnosis penyakit Pneumonia. Pada pengujian P2 dan P4, probabilitas penyakit Bronkhitis mendekati nilai untuk penyakit Pneumonia, setelah dilakukan analisis dengan data pengujian, didapat bahwa gejala untuk penyakit Bronkhitis hampir sama dengan penyakit Pneumonia.

4. Pengujian Penyakit Bronkhitis dengan menggunakan sample data secara acak, didapat hasil seperti pada Gambar 8:

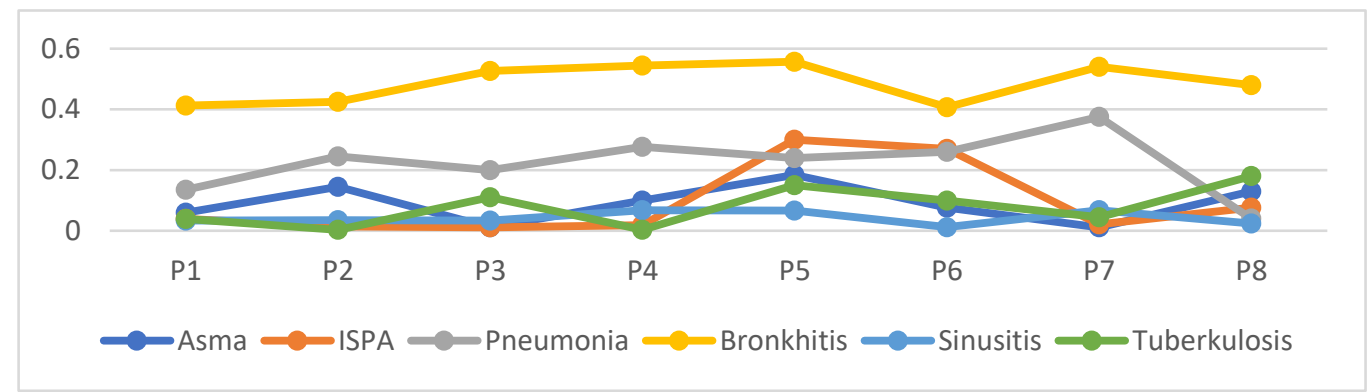

Gambar 8. Hasil Pengujian penyakit Bronkhitis

Dari Gambar dapat dilihat bahwa hasil pengujian menunjukkan bahwa pada pengujian 1 sampai pengujian 4 mendapatkan nilai tertinggi untuk diagnosis penyakit Bronkhitis. Seperti pada pengujian sebelumnya untuk penyakit Pneumonia, nilai probabilitas penyakit Pneumonia hampir mendekati penyakit Bronkhitis, hal ini disebabkan karena gejala penyakitnya hampir sama.

5. Pengujian Penyakit Sinusitis dengan menggunakan sample data secara acak, didapat hasil seperti pada Gambar 9:

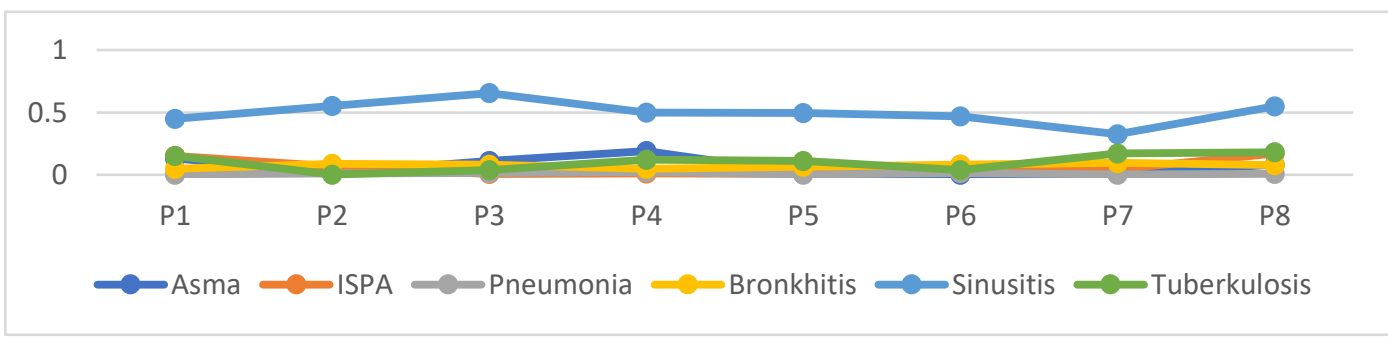

Gambar 9. Hasil Pengujian penyakit Sinusitis 
Dari Gambar dapat dilihat bahwa hasil pengujian menunjukkan bahwa pada pengujian 1 sampai pengujian 8 mendapatkan nilai tertinggi untuk diagnosis penyakit Sinusitis.

6. Pengujian Penyakit Tuberkulosis dengan menggunakan sample data secara acak, didapat hasil seperti pada Gambar 10:

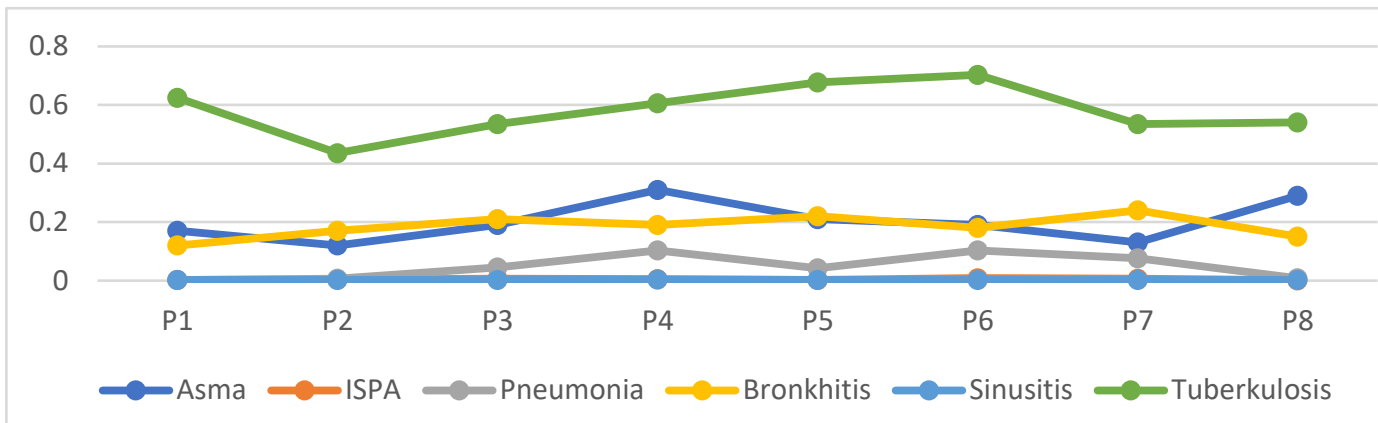

Gambar 10. Hasil Pengujian penyakit Tuberkulosis

Dari Gambar 10 dapat dilihat bahwa hasil pengujian menunjukkan bahwa pada pengujian 1 sampai pengujian 8 mendapatkan nilai tertinggi untuk diagnosis penyakit Tuberkulosis.

\section{KESIMPULAN DAN SARAN}

\subsection{Kesimpulan}

Dari Pemodelan Bayesian Network yang telah dilakukan pada penelitian ini, dapat ditarik kesimpulan bahwa:

1. Struktur Bayesian Network ini dibangun dengan menggunakan metode Scoring based, dengan penerapan nya menggunakan algoritme hill climbing dan dengan fungsi scoring BIC score. Dari 18 variabel menghasilkan 31 arcs yang saling merepresentasi keterhubungan antara gejala dan penyakit saluran pernapasan. Penggunaan metode ini terbukti mampu menghasilkan Bayesian Network yang cukup representatif.

2. Pengujian dengan menggunakan data uji terhadap model Bayesian Network yang dihasilkan, mendapat akurasi sebagai berikut:

- Akurasi benar untuk diagnosis penyakit Asma dengan menggunakan 8 buah data uji adalah, $75 \%$, dan $25 \%$ terdiagnosis salah.

- Akurasi benar untuk diagnosis penyakit ISPA dengan menggunakan 8 buah data uji adalah, $100 \%$,

- Akurasi benar untuk diagnosis penyakit Pneumonia dengan menggunakan 8 buah data uji adalah, $100 \%$,

- Akurasi benar untuk diagnosis penyakit Bronkhitis dengan menggunakan 8 buah data uji adalah, $100 \%$,

- Akurasi benar untuk diagnosis penyakit Sinusitis dengan menggunakan 8 buah data uji adalah, $100 \%$,

- Akurasi benar untuk diagnosis penyakit Tuberkulosis dengan menggunakan 8 buah data uji adalah, $100 \%$,

Secara keseluruhan, akurasi dari masing-masing penyakit sudah menunjukkan hasil yang baik. Struktur Bayesian Network yang dihasilkan sangat dipengaruhi oleh kondisi data, karena itu sebelum 
melakukan konstruksi Bayesian Network, sebaiknya dilakukan data cleaning terlebih dahulu, agar data yang dihasilkan konsisten.

\subsection{Saran}

Saran untuk penelitian berikutnya, dapat menambah jenis peyakit yang diprediksi, karenan pada penelitian yang dilakukan ini hanya terbatas untuk enam jenis penyakit saluran pernapasan, dan dapat mengembangkan model yang dibuat ini ke dalam bentuk Aplikasi, sehingga mudah untuk digunakan oleh masyarakat.

\section{UCAPAN TERIMAKASIH}

Terimakasih untuk Politeknik Negeri Ketapang yang telah menjadi tempat melakukan penelitian, Terimakasih kepada Rumah Sakit Agoes Djam yang telah menyediakan tempat dalam proses pengumpulan data.

\section{DAFTAR PUSTAKA}

[1] [WHO] World Health Organization. 2012. [diacu Mei 2015]/ tersedia dari: http://www.who.int/gard/GARD_sign_up/en/.

[2] Fishman Alfred P, Elias Jack A, Fishman Jay A, Grippi Michael A, Senior Robert M, Pack Alian I. 2008. Fishman's Pulmonary Disease and Disorders. Mc Graw Hill Medical.

[3] Heckerman D. 1995. A Tutorial on Learning with Bayesian Networks. 1.

[4] Holmes PE, Jain PC. 2008. Innovation in Bayesian Networks. Chennai, India: Springer.

[5] Seixas FL, Zadrozny B, Laks J, Conci A, Saade DC. 2014. A Bayesian Network Decision Model for Supporting the diagnosis of Dementia, Alzheimer's disease and mild cognitive impairment. Elsevier.

[6] Sesen MB, Nicholson AE, Alcantara RB, Kadir T, Brady M. 2013. Bayesian Network for Clinical Decision Support in Lung Cancer Care. PLOS, 1-13. 